\title{
O Ensino Religioso nas Escolas Públicas de Goiás
}

\author{
Marcelo Máximo Purificação ${ }^{1}$
}

\section{RESUMO}

O cruzamento entre o Ensino Religioso e as políticas públicas é uma temática essencial para as ciências sociais. Ao longo de nossa vida, crescemos ouvindo que os jesuítas foram os responsáveis pela formação religiosa no Brasil Colônia. Ouvimos também que foram eles os primeiros a introduzirem no nosso país o processo educacional, através da fundação de colégios onde catequizavam os índios e lhes ensinavam a ler e escrever. O presente trabalho está envolto numa temática atual e busca uma reflexão consciente sobre a realidade do Ensino Religioso na educação nas escolas públicas estaduais de Luziânia - GO. Suscita uma discussão sobre a dimensão pedagógica do Ensino Religioso como disciplina curricular e a problemática da formação de professores nesta área do saber.

\section{PALAVRAS-CHAVE}

Educação, Ensino Religioso, Formação de Professores e Currículo.

\section{ABSTRACT}

The crossing between Religious Teaching and Public Politics is an essential subject of Social Sciences. We've heard Jesuits were

\footnotetext{
${ }^{1}$ Docente em Filosofia, Mestre em Ciências Educacionais pela UEP, Mestre em Educação Comunitária com Infầncia e Juventude pela EST/RS e Doutorando em Ciências da Religião pela PUC-Goiás.
} 
responsible for the Religious education in Brazil colonial period, and that they also first introduced the education process in Brazil. In Jesuits Schools Indians were catechized and taught to read and to write. The present work deals with this theme and it also searches for a conscious reflection on the reality of the Religious Teaching in the education in public schools at Luziania - GO. It also raises a discussion on the pedagogic dimension of the Religious Teaching as Curricular Subject and the problem of the teachers' education in this area of knowledge.

\section{KEYWORDS}

Education, Religious Teaching, Teachers Education, Curriculum.

\section{Introdução}

$\mathrm{Na}$ área da educação, podem-se observar diferentes formas e parâmetros cuja finalidade principal é o desenvolvimento pleno do indivíduo na sociedade. O ensino é um caminho pelo qual a educação está apta a acontecer, porém não é o único e nem tampouco o mais importante, mas um dos que mais eficácia apresenta.

O Ensino Religioso não pode perder de vista o seu foco, que é o ser humano no seu tempo e espaço. Daí, sua base antropológico-cultural, isto é, o desenvolvimento pleno do ser humano por meio da satisfação de suas necessidades fundamentais. A dinâmica social de mundo atual estabelece mudanças de valores e comportamentos muito rápidas na sociedade. E o reflexo de tudo isso aparece de forma desigual através de problemas que interferem na vida de todos.

A educação brasileira, ao longo de vários anos, passou por várias reformas, muitas teorias foram entronizadas ao processo educacional. O resultado de tudo isso é uma educação escolar sem identidade, ou seja, o Brasil não tem um perfil educacional. Nossa educação é constituída de vários perfis e, como bem diz Drummond, "cada perfil, com suas meias verdades" $" \mathrm{Na}$ busca de encontrar culpados para o caos

\footnotetext{
${ }^{2}$ ANDRADE, Carlos Drummond de. Verdade. Disponível em: http://www.veraregina.com.br/cantinho/portugue/poe-bras/27.htm. Acesso em 02 maio de 2009.
} 
social, deparamos com questionamentos que tentam responder o despertar de um jovem em situação de vulnerabilidade social. A família, a escola, o governo, a igreja - todos aparecem com uma parcela de culpa. O Estatuto da Criança e do Adolescente apresenta uma série de medidas e intervenções para conter as violências juvenis, cujo caráter preventivo reside na possibilidade de aplicar penalidades rigorosas para atos ilícitos.

\title{
Historicidade do Ensino Religioso O Ensino Religioso no Brasil
}

\begin{abstract}
A educação, como uma chave indispensável para o exercício da cidadania, na sociedade contemporânea, vai se impondo cada vez mais nestes tempos de grandes mudanças e inovações nos processos produtivos. Ela possibilita ao indivíduo jovem e adulto retomar seu potencial, desenvolver suas habilidades, confirmar competências adquiridas na educação extra-escolar e na própria vida, possibilita um nível técnico e profissional mais qualificado33.
\end{abstract}

Nessa trajetória, estudamos os ethos culturais que conferem caráter particular a determinada sociedade, a qual fundamenta toda a sua organização, educacional, social, política, religiosa.

Para Anísia de Paulo Figueiredo ${ }^{4}$, Ensino Religioso, educação e educação religiosa se preocupam e se direcionam a um só destino: o ser humano. Este ser que, por sua vez, caminha a um futuro desconhecido e que carrega consigo as mesmas inquietações filosóficas que sempre acompanharam as pessoas ao longo dos tempos, tais como: Quem sou? Para onde vou? Qual o sentido da vida?

O ser humano começa a busca pela resposta aos seus questionamentos nas situações e experiências religiosas que vivencia, até mesmo

\footnotetext{
${ }^{3}$ SOARES, Magda. Letramento: um tema em três gêneros. Belo Horizonte. Autêntica, 2002, p. 40.

${ }^{4}$ FIGUEIREDO, Anísia de Paulo. Ensino Religioso em chave de reflexão antropológica. Revista Diálogo. São Paulo, v. 1, 1995, p. 10.
} 
nas pequenas situações do dia-a-dia, e procura nos fenômenos religiosos a razão de ser de sua existência, ou seja, o real sentido de seu viver.

Na luta pela vida ou de encontrar um sentido para ela, o adolescente irá perceber a existência divina, ou seja, da própria questão da transcendência. A partir daí, destaca-se a necessidade de se trabalhar com esta religiosidade, respeitando a tradição religiosa que ele já traz de sua família e de suas experiências neste sentido, abrindo espaço para que o mesmo encontre um ambiente propício na sala de aula.

\section{O Ensino Religioso no Brasil: num foco católico}

A presença da espiritualidade é evidente na sociedade brasileira desde seus primórdios. Isto se evidencia na multiplicação de novos movimentos religiosos e no uso difundido de símbolos e enfeites de caráter religioso. Os adolescentes usuários destes símbolos estão mais místicos, mas definem sua religiosidade com liberdade.

A partir desta espiritualidade, genuinamente brasileira, Anísia de Paulo Figueiredo aponta o quadro histórico da origem do Ensino Religioso no Brasil, a partir de um foco católico, a iniciar com a presença dos jesuítas e o seu papel no Brasil Colônia. Ela diz:

Os primeiros passos na formação do povo brasileiro são dados em tempos fortes de exploração de riquezas da terra e de submissão dos nativos aos esquemas da metrópole. O Brasil desde o início é alvo de uma política mercantilista sob o regime do monopólio, que exige estabelecimento de um pacto colonial. [...] propicia a mistura de raças e aparecimento de elementos culturais e religiosos que, somados aos dos costumes indígenas, sob o guarda-chuva do cristianismo e outros elementos da cultura européia, vão dar origens as vertentes por onde passará o Ensino Religioso 5 .

A citação acima deixa clara a análise pessoal da autora que, com precisão, descreve o papel do Estado e das concepções filosóficas refe-

\footnotetext{
${ }^{5}$ FIGUEIREDO, Anísia de Paulo. O ensino religioso no Brasil: tendências, conquistas e perspectivas. Petrópolis: Vozes, 1996, p. 19.
} 
rentes ao Ensino Religioso Escolar na historiografia do Brasil, dividida da seguinte forma:

Colonialismo ${ }^{6}$ : O Ensino Religioso é realizado como cristianização, ou seja, o regime padroado em que a Igreja Católica figurava como religião oficial ${ }^{7}$. A instrução religiosa cabia de direito na legislação escolar e na prática educativa. Evidentemente, tal ordenamento legal e suas aplicações eram bastante questionáveis do ponto de vista da liberdade religiosa.

Regalismo ${ }^{8}$ : O Ensino Religioso é atrelado ao sistema de protecionismo da metrópole para com a religião católica. Sendo que, com a publicação do Decreto 119A, de 7 de janeiro de 1890, fica estabelecida a separação entre Igreja Estado. ${ }^{9}$ Logo a seguir, a Constituição da República dos Estados Unidos do Brasil, de 24 de fevereiro de 1891, declarava o estado laico, sem conotação e posicionamento de índole religiosa, e promulgava também a liberdade religiosa extensivas a todos os indivíduos e grupos, respeitados os princípios da convivência social.

Positivismo $^{10}$ : O Ensino Religioso é tolerado em meio a inúme-

${ }^{6}$ Colonialismo (1500-1800): "Política de exercer o controle ou a autoridade sobre um território ocupado e administrado por um grupo de indivíduos com poder militar, ou por representantes do governo de um país ao qual esse território não pertencia, contra a vontade dos seus habitantes que, muitas vezes, são desapossados de parte dos seus bens (como terra arável ou de pastagem) e de eventuais direitos políticos que detinham". Disponível em: http://pt.wikipedia.org/wiki/Colonialismo. Acesso em: 06 mai. 2009.

${ }^{7}$ RUEDELL, Pedro. Evolução do Ensino Religioso nas escolas oficiais do Rio Grande do sul. São Leopoldo: UNISINOS, 2007, p. 19.

${ }^{8}$ Regalismo (1800-1900): Doutrina que defende a ingerência do chefe de estado em questões religiosas. Disponível em: http://pt.wikipedia.org/wiki/Colonialismo. Acesso em: 06 mai. 2009.

${ }^{9}$ RUEDELL, 2007, p. 20.

${ }^{10}$ Positivismo (1900-1930/34): "Este termo foi empregado pela primeira vez por Saint-Simon, para designar o método exato das ciências e sua extensão para filosofia (De la religion Saint-Simonienne, 1830, p. 3). Foi adotado por Augusto Comte para sua filosofia e, graças a ele, passou a designar uma grande corrente filosófica, que na segunda metade do séc. XIX, teve numerosíssimas e variadas manifestações em todos os países do mundo ocidental. A característica do positivismo é a romantização da ciência, sua devoção como único guia da vida individual e social do homem, único conhecimento, única moral, única religião possível”. ABBAGNANO, Nicola. Dicionário de Filosofia. São Paulo: Martins Fontes, 2000, p. 776. 
ros questionamentos, em que busca a definição devido à compreensão do caráter laico do ensino ministrado nos estabelecimentos públicos. "O caráter facultativo mantinha sua ligação com as confessionalidade e a laicidade dos currículos escolares como um todo"".

Nota-se que o modelo catequético faz parte da vida das confissões religiosas quando elas se sustentam na transmissão de seus princípios de fé, de suas doutrinas e dogmas. O quadro a seguir sintetiza didaticamente alguns aspectos que caracterizam o modelo catequético, segundo Luzia Senna ${ }^{12}$.

Quadro 1: Características do modelo

catequético de Ensino Religioso:

\begin{tabular}{|l|l|}
\hline Cosmovisão & Unirreligiosa \\
\hline Contexto Político & Aliança Igreja - Estado \\
\hline Fonte & Conteúdos doutrinais \\
\hline Métodos & Doutrinação \\
\hline Afinidades & Escola Tradicional \\
\hline Objetivo & Expansão das Igrejas \\
\hline Responsabilidade & Confissões religiosas \\
\hline Riscos & Proselitismo e intolerância \\
\hline
\end{tabular}

Fonte: SENA, 2006.

Outro marco desse período foi o modelo teológico, adotado porque se trata de uma concepção de Ensino Religioso que busca uma fundamentação para além da confessionalidade estrita, de forma a superar a prática catequética. A justificativa teológica vem contextualizada e respaldada por uma cosmovisão religiosa.

A teologia não configura, necessariamente, conteúdos confessionais nas programações de Ensino Religioso, mas age, sobretudo, como um pressuposto que sustenta a convicção dos agentes e a própria motivação da ação: a missão de educar é

${ }^{11}$ SENA, Luiza (Org.). Ensino religioso e formação docente. São Paulo: Paulinas, 2006, p. 29.

${ }^{12}$ SENA, 2006, p. 30. 
firmada como um valor sustentado por uma visão transcendente do ser humano ${ }^{13}$.

Percebe-se que houve discussões fortes entre os que almejavam a oficialização da educação religiosa escolar e os defensores da laicidade do ensino oficial ${ }^{14}$. A religiosidade é, portanto, uma dimensão humana a ser educada, o princípio "fundante" e o objetivo fundamental do Ensino Religioso Escolar. E o conflito entre a ideologia católica e a liberal se acirrou com a instituição da Assembléia Nacional Constituinte de 1933. Os pioneiros defendiam a escola pública capaz de forjar uma nova sociedade mais justa e igualitária.

Quadro 2: Características do modelo teológico de Ensino Religioso:

\begin{tabular}{|l|l|}
\hline Cosmovisão & Plurirreligiosa \\
\hline Contexto Politico & Sociedade Secularizada \\
\hline Fonte & Antropologia, teologia do pluralismo \\
\hline Métodos & Indução \\
\hline Afinidades & Escola Nova \\
\hline Objetivo & Formação Religiosa dos cidadãos \\
\hline Responsabilidade & Confissões religiosas \\
\hline Riscos & Catequese disfarçada \\
\hline
\end{tabular}

Fonte: SENA, 2006.

Nacionalismo ${ }^{15}$ : O Ensino Religioso é admitido em caráter faculta-

${ }^{13}$ SENA, 2006, p. 30.

${ }^{14}$ SENA, 2006, p. 31.

${ }^{15}$ Nacionalismo (1934/37-1945): "O conceito de nação começou a se formar a partir do conceito de povo, que havia dominado a filosofia política do séc. XVIII, quando se acentuou, nesse conceito, a importância dos fatores naturais e tradicionais em detrimentos dos voluntários. O povo é constituído essencialmente pela vontade comum, que é a base do pacto originário; a nação é constituída essencialmente por vínculos independente da vontade dos indivíduos: raça, religião, língua e todos os outros elementos que podem ser compreendidos sob o nome de "tradição". Diferentemente do povo que não existe se não em virtude da vontade deliberada e seus membros e como efeito dessa vontade, a nação nada tem a ver com a vontade dos 
tivo, respeitando-se o direito de participação: o da família e a confissão religiosa do aluno.

Liberalismo ${ }^{16}$ : O Ensino Religioso é contemplado como dever do Estado para com a liberdade religiosa do cidadão.

Depois da Segunda Guerra Mundial, tiveram início grandes mudanças sociais, políticas e culturais, que ganharam ritmo e intensidade após a reconstrução européia, com o auge do desenvolvimento do hemisfério norte e com a difusão de idéias e ações que caracterizavam o surgimento de um novo paradigma sociocultural chamado de pós-modernidade.

Autoritarismo ${ }^{17}$ : O Ensino Religioso é obrigatório para a escola, concedendo ao aluno o direito de opção no ato da matrícula ${ }^{18}$. Nota-se, nos textos legais sobre o Ensino Religioso, uma reiterada atenção à liberdade religiosa dos alunos e de suas famílias, com o objetivo de assegurar-lhes liberdade de escolha diante do Ensino Religioso oferecido pela escola.

Reconstrutivismo ${ }^{19}$ : O Ensino Religioso busca sua identidade, seu espaço e a redefinição de seu papel na escola. O Ensino Religioso é parte integrante da formação básica do cidadão. Constitui elemento in-

indivíduos: é um destino que paira sobre os indivíduos, ao qual estes não podem subtrair sem traição [...]”. ABBAGNANO, 2000, p. 694.

${ }^{16}$ Liberalismo (1945-1964): "Corrente anti-religiosa que se difundiu sobretudo em ambientes eruditos da França e da Itália, na primeira metade do séc. XVII; constitui a reação - em grande parte subterrânea - ao predomínio político do catolicismo naquele período. Não tem idéias filosóficas bem detalhadas, e a ela pertenceram: católicos sinceramente ligados à Igreja, mas que achavam impossível aceitar integralmente sua estrutura doutrinária do paganismo [...]”. ABBAGNANO, 2000, p. 613.

${ }^{17}$ Autoritarismo (1964-1985): "Descreve uma forma de governo caracterizada pela ênfase na autoridade do Estado em uma república ou união. É um sistema político controlado por legisladores não eleitos que usualmente permitem algum grau de liberdade individual". Disponível em: http://pt.wikipedia.org/wiki/Colonialismo. Acesso em 06 mai. 2009.

${ }^{18}$ RUEDELL, 2007, p. 25.

${ }^{19}$ Reconstrutivismo (1985 até os dias atuais): "Refere ao ato de recriar uma série de correntes de pensamento em diferentes áreas do conhecimento (cada uma delas não tem necessariamente relação com as outras)" Disponível em: http://pt.wikipedia. org/wiki/Colonialismo. Acesso em: 06 mai. 2009. 
substituível de educação e desenvolvimento pleno pessoa humana e de construção de uma sociedade justa e solidária.

Contemporaneidade: Com a Lei de Diretrizes e Bases Nacionais em pleno vigor, estabelecem diretrizes a respeito da nova redação do Art. 33.

O Ensino religioso, de matrícula facultativa, é parte integrante da formação básica do cidadão e constitui disciplina dos horários normais das escolas públicas de ensino fundamental, assegurado o respeito à diversidade cultural religiosa do Brasil, vedadas quaisquer formas de proselitismo ${ }^{20}$.

Com o crescimento da diversidade religiosa brasileira e a afirmação de pluralismo religioso insuperável, há, certamente, que se lançar novas bases para reflexão do Ensino Religioso na escola pública. Não há como manter posicionamentos que defendam em âmbito público um ensino confessional, embora no Brasil ainda persistam em casos específicos modelos de Ensino Religioso nessa direção, cuja pluralidade vem reforçada pela Lei 9475, que diz:

Art. 33. O ensino religioso, de matrícula facultativa, é parte integrante da formação básica do cidadão e constitui disciplina dos horários normais das escolas públicas de ensino fundamental, assegurado o respeito à diversidade cultural religiosa do Brasil, vedadas quaisquer formas de proselitismo.

$\S 1^{\circ}$ Os sistemas de ensino regulamentarão os procedimentos para a definição dos conteúdos do ensino religioso e estabelecerão as normas para a habilitação e admissão dos professores.

$\S 2^{\circ}$ Os sistemas de ensino ouvirão entidade civil, constituída pelas diferentes denominações religiosas, para a definição dos conteúdos do ensino religioso ${ }^{21}$.

${ }^{20}$ REPÚBLICA FEDERATIVA DO BRASIL. Casa Civil. Subchefia para assuntos jurídicos. Lei de Diretrizes e Bases da Educação Nacional. Lei n. 9.394. Brasília, 20 dez. 1996. Art. 33. Disponível em: http://www.planalto.gov.br/ccivil_03/LEIS/ 19394.htm. Acesso em 29 abril de 2009.

${ }^{21}$ REPÚBLICA FEDERATIVA DO BRASIL. Casa Civil. Subchefia para assuntos jurídicos. Lei n. 9.475. Brasília, 22 jul. 1997. Art. $1^{\circ}$. Disponível em: http://www. planalto.gov.br/ccivil_03/LEIS/19475.htm. Acesso em 29 abril de 2009. 


\section{O Ensino Religioso e a educação}

$\mathrm{Na}$ educação brasileira, o Ensino Religioso se fez marco por caminhos distintos: a confessionalidade, a inter-confessionalidade e, no atual momento, a inter-religiosidade. De matrícula facultativa, passou a ser parte integrante da formação básica do cidadão.

Nos Parâmetros Curriculares Nacionais - PCNs, o Ensino Religioso atinge um lugar importante na educação brasileira; pela primeira vez, pessoas de vários credos religiosos, enquanto educadores, conseguiram, na unidade, encontrar o que há de comum numa mesma proposta educacional que tem como objeto o Transcendente. Os PCNs do Ensino Religioso compreendem a sistematização do fenômeno religioso, a partir das raízes das tradições religiosas orientais, ocidentais e africanas, para isso, há a necessidade de um profissional de educação sensível à pluralidade e consciente da complexidade sócio-cultural, garantindo a liberdade religiosa do educando.

Não podemos fugir desta realidade, pois a diversidade religiosa está presente em nossa sala de aula. Tal fato não deve ser ignorado, mas respeitado, e o Ensino Religioso deve ser a ponte a sustentar a religiosidade de nosso educando e a valorização de suas tradições religiosas.

Para Laude E. Brandenburg, "[...] o lugar do Ensino Religioso no projeto da escola é um desafio que se apresenta numa organização escolar na qual ele é conhecimento marginalizado"22. Por isso, este conhecimento religioso deve ser colocado ao alcance dos alunos para que eles venham a ampliar sua visão sobre o transcendente. Para isso, na sala de aula, o professor também deve se utilizar de meios e recursos variados para que o educando venha a desenvolver o gosto por esta disciplina e amplie os seus saberes nesta área do conhecimento, desenvolvendo uma visão mais ampla e um olhar mais analítico sobre o fenômeno religioso.

\footnotetext{
${ }^{22}$ BRANDENBURG, Laude E. A interação pedagógica no Ensino Religioso. São
} Leopoldo: Sinodal, 2004, p. 131. 


\section{O Ensino Religioso em Goiás}

No Estado de Goiás, o Conselho Estadual de Educação, fundamentando-se na Constituição Federal, Art. $210^{23}$, e no Art. 162 da Constituição Estadual ${ }^{24}$, no Art. 33 da Lei de Diretrizes de Bases da Educação Nacional, com a redação dada pela Lei n. 9.475/97 e, por último, fundamentando na Resolução n. 285 do Conselho Estadual de Educação, de 09 de dezembro de $2005^{25}$, estabelece critérios para oferta de Ensino Religioso nas Escolas do Sistema Educativo de Goiás.

Em Luziânia - GO, a disciplina é parte integrante do currículo na Educação Básica e a Subsecretaria Regional de Educação, faz valer os critérios Resolução CEE n. 285/05 nas escolas jurisdicionadas.

Veja na integra as disposições da Resolução 285:

O Ensino Religioso, de matricula facultativa, parte integrante da formação básica do cidadão, constitui disciplina de oferta obrigatória, nos horários normais das escolas públicas de ensino fundamental e médio, inclusive de jovens e adultos, assegurado o respeito à diversidade religiosa e cultural do Brasil e a todas as crenças individuais ${ }^{26}$.

A aceitação do Ensino Religioso nas escolas públicas de Goiás em Luziânia - GO gira em torno de $98 \%$ e atende ao um público-alvo de 57.315 alunos, espalhados em 61 escolas, totalizando 1.286 professores, dos quais 64 lecionam a disciplina de Ensino Religioso.

${ }^{23}$ PRESIDÊNCIA DA REPÚBLICA. Casa Civil. Subchefia para Assuntos Jurídicos. Constituição da República Federativa do Brasil. Brasília, 05 out. 1988. Art. 210. Disponível em: http://www.planalto.gov.br/ccivil_03/Constituicao/Constituiçao. htm. Acesso em 27 abril de 2009.

${ }^{24}$ GOVERNO DO ESTADO DE GOIÁS. Constituição do Estado de Goiás. Disponível em: http://www2.senado.gov.br/bdsf/bitstream/id/70434/1/Goias_.pdf. Acesso em 27 abril de 2009.

${ }^{25}$ CONSELHO ESTADUAL DE EDUCAÇÃO DE GOIÁS. Resolução n. 285. Goiânia, 09 dez. 2005.Disponível em: http://www.sgc.goias.gov.br/upload/links/ arq 997 V-RES-285-EN.REL.doc. Acesso em 20 junho de 2008.

${ }^{26}$ CONSELHO ESTADUAL DE EDUCAÇÃO, 2005, Art. $1^{\circ}$. 
O Ensino religioso é área de conhecimento integrante de base nacional comum e visa a subsidiar o aluno na compreensão do fenômeno religioso, presente nas diversas culturas e sistematizado por todas as tradições religiosas, deve ter tratamento igual dado a outras disciplinas da educação básica, no que couber ${ }^{27}$.

Considerada uma disciplina como qualquer outra, o Ensino Religioso nas escolas estaduais de Luziânia é ministrado uma vez por semana em cada turma do $6^{\circ}$ ao $9^{\circ}$ ano do Ensino Fundamental e $1^{\circ}$ ao $3^{\circ}$ ano do Ensino Médio, com uma carga horária total de 36h/a por ano. "Se maior, o aluno que optar pela disciplina Ensino Religioso deve se manifestar por escrito no início do ano letivo, perante a direção da unidade escolar, se menor, a manifestação deve ser formalizada por pais ou responsáveis" 28 .

A Constituição brasileira deixa claro em seu bojo a liberdade de expressão e crença. Mesmo o Ensino Religioso não sendo realizado de forma dogmática nas escolas estaduais de Luziânia - GO, é facultado ao aluno e/ou seu representante legal o direito de fazer a opção pela disciplina. Porém, na subsecretaria Regional de Educação de Luziânia, não há um só registro de dispensa da disciplina.

$\S 1^{\circ}$ - A escola deve apresentar ao aluno, no ato da manifestação, a proposta pedagógica do Ensino Religioso para referenciar sua opção ou não. $\S 2^{\circ}$ - Os estabelecimentos de ensino devem oferecer aos alunos que não optarem pelo Ensino Religioso, no mesmo horário, outros conteúdos de formação geral ${ }^{29}$.

Todavia, cada unidade escolar faz constar em sua proposta pedagógica atividades diferenciadas, voltadas para a diversidade cultural e religiosa.

${ }^{27}$ CONSELHO ESTADUAL DE EDUCAÇÃO, 2005, Art. $2^{\circ}$.

${ }^{28}$ CONSELHO ESTADUAL DE EDUCAÇÃO, 2005, Art. $3^{\circ}$.

${ }^{29}$ CONSELHO ESTADUAL DE EDUCAÇÃO, 2005, Art. $3^{\circ}, \S 1^{\circ}$. 


\section{O Ensino Religioso como disciplina curricular}

Se, como dissemos, a religião está presente em todas as sociedades e momentos da história, fica evidente que ela não pode ausentar-se da vida de uma criança. Remarquemos: independentemente de seguir uma religião formal ou não, todos os seres humanos têm o que chamamos de religiosidade, ou seja, um sentimento que questiona ou crê sobre forças superiores e anteriores que nos podem auxiliar, proteger, punir, apoiar ou castigar. Isso significa que a presença da religiosidade na vida de uma criança, assim como sua reflexão ${ }^{30}$.

O ser humano é um ser social, não tem como viver em sociedade isolando-se como uma ilha. Logo, sofre influência da sociedade e de todos os fatores sociais que sobre ela recai. Olhando por esse contexto, podemos afirmar que o Ensino Religioso faz parte da vida do povo brasileiro e conseqüentemente do seu processo de educação. Acreditar em ser superior que nos criou e, por isso, acolhe, ampara e protege é fundamental na vida de uma criança. Por isso, precisamos de pais religiosos e, por sua vez, coerentes em suas atitudes e fala para criarmos as crianças dentro dos valores éticos e morais daquilo que acreditamos e seguimos.

Neste contexto, a escola entra como mediadora do processo, complementando esta educação religiosa que os pais querem dar aos seus filhos. Logo, fica claro que o papel dos pais é educar e o da escola é reforçar essa educação. O Ensino Religioso é a disciplina escolar propícia para fazer essa ponte de valores, resgatando nossas crianças e jovens para que possam construir sua própria identidade religiosa.

A Resolução n. 02/2007 do Conselho Estadual de Educação do Estado de Goiás, dá nova leitura ao Art. 2 da Resolução 285/05, ficando assim estabelecido:

Art. $2^{\circ}$ - O Art. $6^{\circ}$, caput, da Resolução CEE n. 285/2005, passa a vigorar com a seguinte redação:

${ }^{30}$ SENA, 2006, p. 17. 
“Art. $6^{\circ}$ - Os conteúdos do Ensino Religioso serão ministrados como disciplina a partir do $6^{\circ}$ ano do ensino fundamental, se este for de 9 (nove) anos, e, a partir da $5^{\mathrm{a}}$ série, se a duração deste nível da educação básica ainda for de 8 (oito) anos, e, também, no ensino médio, de acordo com o que for estabelecido no Regimento e na Matriz Curricular da unidade escolar" ${ }^{\prime 31}$.

A Escola Pública dá formação em Luziânia Goiás nos níveis fundamental e médio, cabendo aos alunos e aos pais optarem pela matrícula, como determina a Lei de Diretrizes e Base. Quando a família segue um culto, a tendência é que coloca o filho num local que o forme de acordo com o que acredita.

Uma escola inteligente não pode deixar de fora o conteúdo religioso. Pôr para escanteio essa noção é esquisito, pois, se ela não é estranha à vida, como pode ser estranha à escola? [...] Se a Religião é presença constitutiva das existências humanas, e, desse modo, a educação religiosa é imprescindível, vê-se que o Ensino Religioso, como a ordenação intencional desse conteúdo no espaço escolar, torna-se tão sério quanto qualquer outro componente pedagógico, obrigando-nos a desenvolver a nossa competência para tal empreita ${ }^{32}$.

No fragmento de texto acima, a autora nos conduz ao centro da polêmica discussão sobre a aplicabilidade da práxis religiosa no processo educacional, porém cabe ressaltar que, "se a religião é presença constitutiva das existências humanas", toda proposta pedagógica que visa a integração da disciplina na matriz curricular deve ser fundamentada na diversidade cultural e religiosa fazendo links com a transversalidade de temas, lembrando que Ensino Religioso não é uma aula de boas maneiras, não é uma aula de catequese, não é uma aula de

${ }^{31}$ CONSELHO ESTADUAL DE EDUCAÇÃO DE GOIÁS. Resolução n. 2. Goiânia, 02 fev. 2007. Disponível em: http://www.cee.go.gov.br/index.php?idMateria=18829. Acesso em 02 maio de 2009.

${ }^{32}$ SENA, 2006, p. 19. 
história... Enfim, Ensino Religioso não é qualquer coisa. A verdade é que uma coisa é certa: a felicidade do ser humano está brevemente associada a Deus.

Segundo Ruedell,

A dimensão religiosa, com a qual sintonizamos é algo que nos toca incondicionalmente. Algumas destas preocupações podem ser urgentes e imprescindíveis, tornando-se insistentemente apelativas, significando para as pessoas envolvidas algo de suprema concernência ${ }^{33}$.

Ruedell chama a atenção, neste contexto, para a dimensão do Ensino Religioso, lembrando da necessidade de superar uma posição monopolista e proselitista, para que haja uma autêntica educação da religiosidade inserida no sistema público de educação em benefício do povo. Ele mesmo afirma que

O ponto de partida do ER não é mais a entidade religiosa igreja e sim a entidade educacional escola. À escola, que possibilita o acesso ao conhecimento produzido pela humanidade, bem como ao Ensino Religioso, compete integrar, numa visão de totalidade, os vários níveis de conhecimento, sensorial, intuitivo, afetivo, racional, artístico e religioso ${ }^{34}$.

\section{A formação de docente de Ensino Religioso}

Educação é o conjunto dos processos de socialização e desenvolvimento integral, dados em qualquer instância ou instituição social, seja com vivência ocasional -"vivendo e prendendo"

\footnotetext{
${ }^{33}$ RUEDELL, 2007, p. 44.

${ }^{34}$ DEON, José; BRANDENBURG, Laude Erandi. Ensino Religioso como área do conhecimento no ensino médio. In: BRANDENBURG, Laude E.; KLEIN, Remí; WACHS, Manfredo C. (Orgs.). Ensino Religioso: diversidade e identidade: V Simpósio de Ensino Religioso. 29-31 mai. 2008. São Leopoldo: Sinodal, 2008, p. 148.
} 
- seja com uma intenção e propósito. Assim também a educação religiosa se dá o tempo todo, com qualquer idade e em qualquer nível e patamar da vida social, pelo contato com a presença do fenômeno religioso no meio social e das adesões e rejeições das pessoas a ele ${ }^{35}$.

A necessidade de se discutir sobre a problemática da identidade pedagógica do Ensino Religioso e da formação dos docentes que atuam na área está no seu próprio contexto histórico, a partir do momento que este passou a ser concebido como parte integrante da educação. Por isso, discutir características para uma boa prática pedagógica da disciplina é fundamental.

A própria LDB estabelece que a formação de docentes para atuar na educação básica "far-se-á em nível superior, em cursos de licenciaturas, de graduação plena" 36 . O presente artigo foca para um avanço na proposta educativa e para dificuldade para sua implantação, conforme afirma equipe técnica da Subsecretaria Regional de Educação de Luziânia, que gerenciam mais 50 mil alunos distribuídos em Ensino Fundamental e Médio, com aproximadamente 64 professores ministrando o Ensino Religioso, sendo que nenhum possui licenciatura plena em Ciências da Religião.

Nesta perspectiva, o Ensino Religioso, como componente curricular, fundamenta-se na pluralidade cultural da sociedade. Para isso, é fundamental que o profissional dessa disciplina tenha uma formação específica que o habilite e qualifique nessa área do conhecimento.

Hoje no Brasil, as principais instituições que trabalham com a formação de docente para o Ensino Religioso podem ser visualizadas no quadro abaixo ${ }^{37}$ :

${ }^{35}$ CORTELLA, Mário Sérgio. Educação, Ensino Religioso e formação docente. Diálogo. São Paulo, v. 45, 2007, p. 22.

${ }^{36}$ REPÚBLICA FEDERATIVA DO BRASIL, 1996, Art. 62.

${ }^{37}$ SENA, 2006, pp. 105-109. 
Quadro 3: Instituições de formação de docentes para o Ensino Religioso:

\begin{tabular}{|c|c|c|}
\hline LOCALIDADE & CURSOS & INSTITUIÇÃO \\
\hline BA - Salvador & $\begin{array}{l}\text { Bacharelado em Ciências da } \\
\text { Religião }-2.720 \mathrm{~h} / \mathrm{a}\end{array}$ & Faculdade Social da Bahia \\
\hline DF - Brasília & $\begin{array}{l}\text { Especialização em Ensino } \\
\text { Religioso (distância) - } 436 \text { h/a }\end{array}$ & $\begin{array}{l}\text { Universidade Católica de } \\
\text { Brasília (UCB) }\end{array}$ \\
\hline DF - Brasília & $\begin{array}{l}\text { Bacharelado em Ensino } \\
\text { Religioso } 2.368 \mathrm{~h} / \mathrm{a}\end{array}$ & $\begin{array}{l}\text { Escola Superior de } \\
\text { Teologia e Filosofia do } \\
\text { Brasil (ESTEFIB) }\end{array}$ \\
\hline ES-Vitória & Especialização - 360 h/a & $\begin{array}{l}\text { Faculdade Unida de } \\
\text { Vitória }\end{array}$ \\
\hline ES-Vitória & $\begin{array}{l}\text { Mestrado Profissional em } \\
\text { Ciências das Religiões }\end{array}$ & $\begin{array}{l}\text { Faculdade Unida de } \\
\text { Vitória }\end{array}$ \\
\hline GO - Goiânia & Especialização - $375 \mathrm{~h} / \mathrm{a}$ & $\begin{array}{l}\text { Universidade Católica do } \\
\text { Goiás (UCG) }\end{array}$ \\
\hline GO - Goiânia & $\begin{array}{l}\text { Pós-Graduação Stricto Sensu } \\
\text { em Ciências da Religião } \\
\text { (Mestrado e Doutorado) }\end{array}$ & $\begin{array}{l}\text { Universidade Católica de } \\
\text { Goiás (UCG) }\end{array}$ \\
\hline $\begin{array}{l}\text { MG-Belo } \\
\text { Horizonte }\end{array}$ & $\begin{array}{l}\text { Licenciatura em Pedagogia } \\
\text { com ênfase em Ensino } \\
\text { Religioso }-2.560 \mathrm{~h} / \mathrm{a}\end{array}$ & $\begin{array}{l}\text { Pontifícia Universidade } \\
\text { Católica de Minas Gerais } \\
\text { (PUC-MG) }\end{array}$ \\
\hline $\begin{array}{l}\text { MG - Belo } \\
\text { Horizonte }\end{array}$ & Especialização - 360 h/a & $\begin{array}{l}\text { Pontifícia Universidade } \\
\text { Católica de Minas Gerais } \\
\text { (PUC-MG) }\end{array}$ \\
\hline MG - Juiz de Fora & $\begin{array}{l}\text { Licenciatura em Ciência da } \\
\text { Religião }\end{array}$ & $\begin{array}{l}\text { Universidade Federal de } \\
\text { Juiz de Fora - MG }\end{array}$ \\
\hline MG - Juiz de Fora & $\begin{array}{l}\text { Pós-Graduação Stricto Sensu } \\
\text { em Ciência da Religião } \\
\text { (Mestrado e Doutorado) }\end{array}$ & $\begin{array}{l}\text { Universidade Federal de } \\
\text { Juiz de Fora - MG }\end{array}$ \\
\hline PA-Belém & $\begin{array}{l}\text { Licenciatura em Ciências da } \\
\text { Religião }-3.200 \mathrm{~h} / \mathrm{a}\end{array}$ & $\begin{array}{l}\text { Universidade Estadual do } \\
\text { Pará (UEPA) }\end{array}$ \\
\hline PA-Belém & $\begin{array}{l}\text { Mestrado em Ciências da } \\
\text { Religião }\end{array}$ & $\begin{array}{l}\text { Universidade Estadual do } \\
\text { Pará (UEPA) }\end{array}$ \\
\hline PA-Belém & Especialização $-390 \mathrm{~h} / \mathrm{a}$ & $\begin{array}{l}\text { Instituto Esperança de } \\
\text { Ensino Superior (IESPES) }\end{array}$ \\
\hline PB - João Pessoa & $\begin{array}{l}\text { Licenciatura em Ciências das } \\
\text { Religiões }\end{array}$ & $\begin{array}{l}\text { Universidade Federal da } \\
\text { Paraíba (UFPB) }\end{array}$ \\
\hline PB - João Pessoa & $\begin{array}{l}\text { Mestrado em Ciências das } \\
\text { Religiões }\end{array}$ & $\begin{array}{l}\text { Universidade Federal da } \\
\text { Paraíba (UFPB) }\end{array}$ \\
\hline
\end{tabular}




\begin{tabular}{|c|c|c|}
\hline LOCALIDADE & CURSOS & INSTITUIÇÃO \\
\hline PR - Curitiba & Especialização - 360 h/a & $\begin{array}{l}\text { Pontifícia Universidade } \\
\text { Católica do Paraná (PUC- } \\
\text { PR) }\end{array}$ \\
\hline PR - Curitiba & $\begin{array}{l}\text { Curso de Extensão - } \\
\text { Qualificação em Ensino } \\
\text { Religioso - } 10 \mathrm{~h} / \mathrm{a}\end{array}$ & Instituto Pólis Civita \\
\hline PR - Curitiba & $\begin{array}{l}\text { Especialização em Ensino } \\
\text { Religioso - } 360 \mathrm{~h} / \mathrm{a}\end{array}$ & Faculdade Baagozzi \\
\hline PR-Curitiba & $\begin{array}{l}\text { Especialização em Ensino } \\
\text { Religioso } 420 \mathrm{~h} / \mathrm{a}\end{array}$ & $\begin{array}{l}\text { Faculdade Teológica } \\
\text { Batista }\end{array}$ \\
\hline PE-Recife & $\begin{array}{l}\text { Especialização em Ensino } \\
\text { Religioso - } 24 \text { meses }\end{array}$ & $\begin{array}{l}\text { Universidade Católica de } \\
\text { Pernambuco (UNICAP) }\end{array}$ \\
\hline PE-Recife & $\begin{array}{l}\text { Mestrado em Ciências da } \\
\text { Religião }\end{array}$ & $\begin{array}{l}\text { Universidade Católica de } \\
\text { Pernambuco (UNICAP) }\end{array}$ \\
\hline $\begin{array}{l}\text { RJ-Rio de } \\
\text { Janeiro }\end{array}$ & $\begin{array}{l}\text { Magistério do Ensino } \\
\text { Religioso em Educação Básica } \\
\text { - Curso livre - } 735 \text { h/a }\end{array}$ & $\begin{array}{l}\text { Faculdade Batista do Rio } \\
\text { de Janeiro }\end{array}$ \\
\hline RN - Natal & $\begin{array}{l}\text { Licenciatura em Ciências da } \\
\text { Religião }-2.790 \mathrm{~h} / \mathrm{a}\end{array}$ & $\begin{array}{l}\text { Universidade do Estado } \\
\text { do Rio Grande do Norte }\end{array}$ \\
\hline $\begin{array}{l}\text { RS - Ijuí e Santa } \\
\text { Rosa }\end{array}$ & $\begin{array}{l}\text { Curso de Extensão } \\
\text { Universitária em Ensino } \\
\text { Religioso }\end{array}$ & $\begin{array}{l}\text { Universidade de ljuí } \\
\text { (UNIJUÍ) }\end{array}$ \\
\hline RS - Pelotas & $\begin{array}{l}\text { Curso de Extensão para } \\
\text { Professores de Ensino } \\
\text { Religioso - } 400 \mathrm{~h} / \mathrm{a}\end{array}$ & $\begin{array}{l}\text { Universidade Católica de } \\
\text { Pelotas }\end{array}$ \\
\hline RS - Porto Alegre & $\begin{array}{l}\text { Curso de Extensão em Ensino } \\
\text { Religioso - } 40 \mathrm{~h} / \mathrm{a}\end{array}$ & $\begin{array}{l}\text { Pontifícia Universidade } \\
\text { Católica do Rio Grande } \\
\text { do Sul (PUC -RS) }\end{array}$ \\
\hline RS - Santa Cruz & $\begin{array}{l}\text { Ciências da Religião e } \\
\text { Qualificação de Professores } \\
\text { para o Ensino Religioso - } \\
\text { Extensão } 420 \mathrm{~h} / \mathrm{a}\end{array}$ & $\begin{array}{l}\text { Universidade de Santa } \\
\text { Cruz do Sul (UNISC) }\end{array}$ \\
\hline $\begin{array}{l}\text { RS - São } \\
\text { Leopoldo }\end{array}$ & Especialização - $400 \mathrm{~h} / \mathrm{a}$ & $\begin{array}{l}\text { Universidade dos Vales } \\
\text { dos Sinos (UNISINOS) }\end{array}$ \\
\hline $\begin{array}{l}\text { RS - São } \\
\text { Leopoldo }\end{array}$ & Especialização & $\begin{array}{l}\text { EST - Escola Superior de } \\
\text { Teologia }\end{array}$ \\
\hline $\begin{array}{l}\text { RS - São } \\
\text { Leopoldo }\end{array}$ & $\begin{array}{l}\text { Pós-Graduação Stricto Sensu } \\
\text { (Mestrado e Doutorado) }\end{array}$ & $\begin{array}{l}\text { EST - Escola Superior de } \\
\text { Teologia }\end{array}$ \\
\hline SC Blumenau & $\begin{array}{l}\text { Licenciatura em Ciências da } \\
\text { Religião }-2.916 \mathrm{~h} / \mathrm{a}\end{array}$ & $\begin{array}{l}\text { Fundação Universidade } \\
\text { Regional de Blumenau } \\
\text { (FURB) }\end{array}$ \\
\hline
\end{tabular}


REFLEXUS - Revista de Teologia e Ciências das Religiões

\begin{tabular}{|l|l|l|}
\hline \multicolumn{1}{|c|}{ LOCALIDADE } & \multicolumn{1}{|c|}{ CURSOS } & \multicolumn{1}{|c|}{ INSTITUIÇÃo } \\
\hline SC-Chapecó & $\begin{array}{l}\text { Licenciatura em Ciências da } \\
\text { Religião }-2820 \mathrm{~h} / \mathrm{a}\end{array}$ & $\begin{array}{l}\text { Universidade Comunitária } \\
\text { da Região de Chapecó } \\
\text { (UNOCHAPECÓ) }\end{array}$ \\
\hline SC - Joinville & $\begin{array}{l}\text { Licenciatura em Ciências da } \\
\text { Religião }-2.840 \mathrm{~h} / \mathrm{a}\end{array}$ & $\begin{array}{l}\text { Universidade Regional de } \\
\text { Joinville (UNIVILLE) }\end{array}$ \\
\hline SC - São José & $\begin{array}{l}\text { Licenciatura em Ciências da } \\
\text { Religião }-3060 \mathrm{~h} / \mathrm{a}\end{array}$ & $\begin{array}{l}\text { Centro Universitário } \\
\text { Municipal de São José } \\
\text { (USJ) }\end{array}$ \\
\hline SE - Aracaju & $\begin{array}{l}\text { Licenciatura em Ciências da } \\
\text { Religião }\end{array}$ & $\begin{array}{l}\text { Universidade Federal de } \\
\text { Sergipe (UFS) }\end{array}$ \\
\hline SE-Aracaju & $\begin{array}{l}\text { Mestrado em Ciências da } \\
\text { Religião }\end{array}$ & $\begin{array}{l}\text { Universidade Federal de } \\
\text { Sergipe (UFS) }\end{array}$ \\
\hline SP - Piracicaba & $\begin{array}{l}\text { Licenciatura em Ciências da } \\
\text { Religião }-2.460 \text { h/a }\end{array}$ & $\begin{array}{l}\text { Universidade Metodista } \\
\text { (UNIMEP) }\end{array}$ \\
\hline $\begin{array}{l}\text { SP }- \text { São Bernardo } \\
\text { do Campo }\end{array}$ & $\begin{array}{l}\text { Pós-Graduação Stricto Sensu } \\
\text { em Ciências da Religião } \\
\text { (Mestrado e Doutorado) }\end{array}$ & $\begin{array}{l}\text { Universidade Metodista } \\
\text { de São Paulo (UMESP) }\end{array}$ \\
\hline SP - São Paulo & $\begin{array}{l}\text { Pós-Graduação Stricto Sensu } \\
\text { em Ciências da Religião } \\
\text { (Mestrado) }\end{array}$ & $\begin{array}{l}\text { Universidade } \\
\text { Presbiteriana Mackenzie }\end{array}$ \\
\hline
\end{tabular}

No Estado de Goiás, a formação docente legalmente constituída está estabelecida na Resolução n. 285 do Conselho Estadual de Educação e nos cursos de Ciência da Religião, nas modalidades licenciatura, especialização, mestrado e doutorado, oferecidos por instituições devidamente credenciadas pelo Ministério da Educação Cultura, como os cursos da Universidade Católica de Goiás, que possui uma linha de pesquisa em plena expansão nesta área do conhecimento. Na regional de Luziânia, não temos professor habilitado. A disciplina é ministrada por profissionais de áreas do conhecimento afins.

O professor, a instituição ou órgão administrativo, atentos a uma boa condução, baseando-se em uma síntese situacional que demonstre necessidade e aponte para elementos enriquecedores a serem valorizados, poderão discernir aspectos a priorizar. Tais conspectos visuais serão necessariamente comple- 
mentares: pôr em destaque um deles repercute no conjunto do crescimento $^{38}$.

Para gozo de direito de regência na Educação Básica de Goiás, é necessário que os professores se enquadrem nos dispositivos da Resolução n. 285/05 que diz:

Art. $9^{\circ}$ - Os professores de Ensino Religioso devem ser integrantes efetivos do quadro do Magistério da Secretaria de Estado da Educação, obedecendo ao princípio constitucional de investidura em cargo público.

Art. 10 - A formação dos professores licenciados efetivos, do Quadro de Magistério da SEE- Secretaria de Estado da Educação, para o exercício da docência no Ensino Religioso, far-se-á em:

I - cursos de formação para o Ensino Religioso, fornecidos pela SEE - Secretaria de Estado da Educação, com carga horária mínima cumulativa de 360 (trezentos e sessenta) horas presenciais, de capacitação, a serem autorizados pelo Conselho Estadual de Educação;

II - curso de graduação em nível de licenciatura em Ciências da Religião ou em Ensino Religioso;

III - curso de pós-graduação lato sensu e strictu-sensu, em Ciências da Religião, em Ensino Religioso ou equivalente.

Parágrafo único: Constitui pré-requisito para a docência de Ensino Religioso, a formação conforme descrito nos incisos I, II e III, o credenciamento feito pela Secretaria de Estado da Educação e encaminhado para cadastramento na Comissão Interconfessional de Ensino Religioso ${ }^{39}$.

Segundo Mário Sérgio Cortella, "o ensino é um dos caminhos da educação, nem sempre o mais perene e emancipador, porém um dos mais eficazes" ${ }^{40}$.

\footnotetext{
${ }^{38}$ RUEDELL, 2007, p. 146.

${ }^{39}$ CONSELHO ESTADUAL DE EDUCAÇÃO, 2005, Art. $9^{\circ}, 10$.

${ }^{40}$ CORTELLA, 2007, p. 22.
} 
A construção da competência do docente de Ensino Religioso, por ser área profundamente delicada e usualmente polêmica, carece de maior substância e necessita ser feita de forma embasada, consistente e metódica, com os recursos e reflexões da didática e da pedagogia sobre os processos educativos ${ }^{41}$.

A problemática do Ensino Religioso em Luziânia vai além da falta de formação dos docentes. A maneira como a disciplina é vista pelos profissionais da educação suscita um problema ainda maior. Muitas vezes, não há um reconhecimento disciplinar por parte de alunos e professores. Os primeiros acham que os conteúdos não são agradáveis e colaboram pouco para sua prática no dia-a-dia. Os segundos utilizam a disciplina como complementação de carga horária. É claro que não podemos generalizar tal fato, até porque estamos falando de uma Regional de Educação que incorpora em sua jurisdição cinco cidades, o que representa um universo de mais de 50 mil alunos e de dezenas de centenas de professores.

\section{Considerações finais}

Este trabalho consistiu em apresentar o Ensino Religioso no estado de Goiás, tendo como análise a região do entorno sul do Distrito Federal. Percebemos que nesse contexto há um debate complexo, pois atrai ao cenário acadêmico sugestões e opiniões diversas. Colocamos no debate um grau maior de complexidade sobre a natureza confessional e a necessidade se trabalhar um Ensino Religioso sem proselitismo religioso.

Partimos do processo histórico de chegada do Ensino Religioso nas primeiras comunidades brasileiras, por meio dos Jesuítas e, a partir daí, estudamos dentro de um contexto nacional na atualidade tendo por base as concepções teóricas de Luzia Senna e os Parâmetros Curriculares Nacionais da Educação, onde a ética é o nosso aporte principal,

${ }^{41}$ CORTELLA, 2007, p. 25. 
calcado, na Lei de Diretrizes e Bases da Educação Nacional. Nessa reconstrução histórica do Ensino Religioso como disciplina escolar, apreciamos o processo de formação dos professores e a importância da disciplina no currículo escolar. Tudo isso, tendo com pano de fundo, ou melhor, dizendo, como cenário, a educação religiosa no Estado de Goiás, fundamentada na Resolução n. 285/05 do Conselho Estadual de Educação.

\section{Referências}

ANDRADE, Carlos Drummond de. Verdade. Disponível em: http:// www.veraregina.com.br/cantinho/portugue/poe-bras/27.htm . Acesso em: 02 mai. 2009.

ARIÈS, Philippe. História social da criança e da família. $2^{\mathrm{a}}$ ed., Rio de Janeiro: LTC, 1981.

BRANDENBURG, Laude E. A interação pedagógica no Ensino Religioso. São Leopoldo: Editora Sinodal, 2004.

CARMO, Paulo Sérgio do. Culturas da rebeldia: a juventude em questão. $2^{\mathrm{a}}$ ed., São Paulo: SENAC, 2001.

Colonialismo (1500-1800). Disponível em: http://pt.wikipedia.org/ wiki/Colonialismo. Acesso em: 06 mai. 2009.

CONSELHO ESTADUAL DE EDUCAÇÃO DE GOIÁS. Resolução n. 2. Goiânia, 02 fev. 2007. Disponível em: http://www.cee.go.gov. br/index.php?idMateria=18829. Acesso em: 02 mai. 2009.

CONSELHO ESTADUAL DE EDUCAÇÃO DE GOIÁS. Resolução n. 285. Goiânia, 09 dez. 2005. Disponível em: http://www.sgc.goias. gov.br/upload/links/arq 997 V-RES-285-EN.REL.doc. Acesso em: 20 jun. 2008.

CORTELLA, Mário Sérgio. Educação, Ensino Religioso e formação docente. Diálogo, São Paulo, v. 45, 2007.

DEON, José; BRANDENBURG, Laude Erandi. Ensino Religioso como área do conhecimento no ensino médio. In: BRANDENBURG, Laude E.; KLEIN, Remí; WACHS, Manfredo C. (Orgs.). Ensino Religioso: diversidade e identidade: V Simpósio de Ensino Religioso. 29-31 mai. 2008. São Leopoldo: Sinodal, 2008. 
DIETZSCH, M. J. M. Ler a cidade e escrever a cidadania. Tempo Brasileiro. Rio de Janeiro, v. 120, pp. 43-56, 1995.

FIGUEIREDO, Anísia de Paulo. Ensino Religioso em chave de reflexão antropológica. Revista Diálogo, São Paulo, v. 1, 1995.

FIGUEIREDO, Anísia de Paulo. O ensino religioso no Brasil: tendências, conquistas e perspectivas. Petrópolis: Vozes, 1996.

GOVERNO DO ESTADO DE GOIÁS. Constituição do Estado de Goiás. Disponível em: http://www2.senado.gov.br/bdsf/bitstream/ id/70434/1/Goias_.pdf. Acesso em: 27 abr. 2009.

HEIDEGGER, Martin. Ser e tempo: parte 1. Petrópolis: Editora Vozes, 1988.

HOLANDA, Chico Buarque. O meu guri. Almanaque. Universal, 1982. Faixa 3 (3 min 54 s.).

Liberalismo (1945-1964). ABBAGNANO, Nicola. Dicionário de Filosofia. São Paulo: Martins Fontes, 2000.

MINISTÉRIO DA EDUCAÇÃO E DO DESPORTO. Conselho Nacional de Educação parecer. Parecer n. 05. Brasília, 11 mar. 1997. Disponível em: http://portal.mec.gov.br/cne/arquivos/pdf/PNCP0597. pdf. Acesso em: 27 abr. 2008.

Nacionalismo (1934/37-1945). ABBAGNANO, Nicola. Dicionário de Filosofia. São Paulo: Martins Fontes, 2000.

Positivismo (1900-1930/34). ABBAGNANO, Nicola. Dicionário de Filosofia. São Paulo: Martins Fontes, 2000.

PRESIDÊNCIA DA REPÚBLICA. Casa Civil. Subchefia para Assuntos Jurídicos. Constituição da República Federativa do Brasil. Brasília, 05 out. 1988. Disponível em: http://www.planalto.gov.br/ ccivil_03/Constituicao/Constituiçao.htm. Acesso em: 27 abr. 2009.

Reconstrutivismo (1985 até os dias atuais). Disponível em: http:// pt.wikipedia.org/wiki/Colonialismo. Acesso em: 06 mai. 2009.

Regalismo (1800-1900). Disponível em: http://pt.wikipedia.org/wiki/ Colonialismo. Acesso em: 06 mai. 2009.

REPÚBLICA FEDERATIVA DO BRASIL. Casa Civil. Subchefia para assuntos jurídicos. Estatuto da Criança e do Adolescente. Lei n. 8.069. Brasília, 13 jul. 1990. Disponível em: http://www.planalto. gov.br/ccivil_03/LEIS/18069.htm. Acesso em: 29 abr. 2009. 
REPÚBLICA FEDERATIVA DO BRASIL. Casa Civil. Subchefia para assuntos jurídicos. Lei de Diretrizes e Bases da Educação Nacional. Lei n. 9.394. Brasília, 20 dez. 1996. Disponível em: http://www. planalto.gov.br/ccivil_03/LEIS/19394.htm. Acesso em: 29 abr. 2009. REPÚBLICA FEDERATIVA DO BRASIL. Casa Civil. Subchefia para assuntos jurídicos. Lei n. 9.475. Brasília, 22 jul. 1997. Disponível em: http://www.planalto.gov.br/ccivil_03/LEIS/19475.htm. Acesso em: 29 abr. 2009.

RUEDELL, Pedro. Evolução do Ensino Religioso nas escolas oficiais do Rio Grande do Sul. São Leopoldo: UNISINOS, 2007.

SENA, Luiza (org.). Ensino religioso e formação docente. São Paulo: Paulinas, 2006. 